DOI: $10.20287 /$ doc.d20.en1

\title{
"Direct cinema is anything but a fly on the wall": a conversation with Albert Maysles
}

\author{
Frank Verano*
}

\begin{abstract}
Albert Maysles, along with his brother David, was a pioneer in American observational documentary in the early 1960s. Revolutionary technological breakthroughs developed by Maysles, producer Robert Drew, and filmmakers Ricky Leacock and D.A. Pennebaker allowed sound and image to be recorded in complete synchronization independent of any physical connectivity; this provided filmmakers a manageable mobility that positioned them to observe and interact with the world in a new way in pursuit of a new cinematic realism. In 1964, Albert coined a term for their practice, which thus distinguished it from the arbitrarily-applied misnomer cinéma vérité: direct cinema.

With Albert behind the camera and David recording sound, the Maysleses sought a modern cinematic expression of both the everyday and the extraordinary that emphasized a spontaneous present-ness. Their early work exploring performativity and lives on the run set the stage: (Showman [1963], What's Happening! The Beatles in the USA [1964], Cut Piece [1965], Meet Marlon Brando [1966] and A Visit With Truman Capote [1966]). Cut Piece was just the beginning of the Maysleses' new cinematic engagement with modern art, which continued in the 1970s in a series of films with Christo and JeanneClaude: Christo's Valley Curtain (1974), Running Fence (1978) and Islands (1986). Their suite of films in the late 1960s and early '70s represents a furthering of the concept of direct cinema, with an increased emphasis on reflexivity in each. Three films constitute their peak direct cinema: Salesman (1969), which explores a cinematic equivalent of Truman Capote's "nonfiction novel"; Gimme Shelter (1970) asks questions pertaining to constructing vision and complicity at Altamont; and Grey Gardens (1975), where this reflexivity reaches its apex. All three continue to be controversial works and remain at the forefront of discussions on documentary ethics.

My conversation with Mr. Maysles took place on November 6, 2012 at the Maysles Films offices in Harlem. It was conducted during a week-long research trip in New York that also gave me the opportunity to explore the rich material history stored in the Maysles brothers' paper archives housed at Columbia University. Our discussion begins with the utopic potentiality

* University of Sussex, School of Media, Film and Music, Brighton, United Kingdom BN1 9RG. E-mail: f.verano@sussex.ac.uk
\end{abstract}


of documentary film and ends with Mr. Maysles on a train, saying goodbye. Sadly, Albert Maysles passed away on March 5, 2015.

FV: I'd like to start with the advent of direct cinema in the 1960s and develop a framework within which we can discuss it. Would you call direct cinema a movement? A technique? An aesthetic? How can I contextualize it?

AM: I guess it's all three. It got started in America with a film called Primary [1960], which was produced by Bob Drew. [Ricky] Leacock and [D.A.] Pennebaker and I did the filming, and we all pitched in on the editing, except for me - I didn't have that kind of skill.

We fully understood the implications, that it was something new in documentary - no host, no narrator, no interviews - all of which more directly, more closely represented what's taking place. And, in a way - in a very important way - [it was also] more authentic, since nothing was staged. That's exactly the kind of information that we need. And to such an extent did we need it that, with all of television at our disposal, more documentaries made in this fashion could give us a very truthful rendition of what's going on in the world, and brings us closer to everybody that the film is filming. And I believe that it could have had a great effect on us [as a country] if we had done more documentaries on the Iraqi people [prior to the second Iraq War]. Even just one documentary would have helped out, so that we would know that if there were a war, that it would not only be soldiers but civilians who would probably be most endangered. We have a desperate need for that.

FV: How did the sync sound and lightweight camera technology affect your filmmaking practice? What did it allow you to do?

AM: Well, with my first film, Psychiatry in Russia, which I shot in 1955, I was terribly out of touch with what had been recorded, because I didn't have any sound, so I had to use narration all the way through. I would have been able to film actual therapy going on, but there was no point in doing that without being able to record sound, so it really hurt the possibility of what I could have been doing. But, at that time, there were documentaries that were being made without sound - or with very poor sound - and those that were made with sound required a number of people. It was a crew, so it wasn't just a soundman and a cameraman, which is what developed in making Primary. Also, I was able to design my own camera in such a fashion that I could carry the 25, 26 pounds very easily, all day long, because it was made so that I could carry it on my shoulder. It made for better shooting, too, because I would be at the same eye level as the people I was filming. 
Another development with Primary was to design the camera such that it and the sound recorder didn't have to be connected to one another, which would tie the soundman down. The motor of the camera was synchronized with the electronic signal that was given to control the tape speed, and so that they ran perfectly parallel to one another, and the sound person could be anywhere, or at least very close. We also did something that still should be general practice, but isn't. We used a directional microphone for the sound person, so that it wasn't this boom hanging over the person's head, something that they would always be afraid might drop on them, and we employed technology that made the camera very, very quiet, so that the sound of the camera never was a problem.

And the cameras are getting better and better all the time. The camera that I put together was 26 pounds - that's a lot to carry. Also, the magazines held 400 feet of film, which is only 10 minutes. Every 10 minutes of shooting, you have to change the camera, which is quite a burden.

FV: How did all of that - the weight of the camera, positioning it on your shoulder - affect your maneuverability and the way in which you engaged with your subjects in a situation?

AM: Actually, I made a few other design changes that helped out a lot. The ring around the lens, which gave us the information about the f-stops - I had put another ring on, which gave bigger numbers, and I set up a mirror - a small mirror - at the front of the lens, so that as I looked at the mirror, I could see the f-stops, and it wasn't necessary for me to put the camera down to change stops. I could - without having to move the camera at all - at any moment in time, know what the f-stop was and could control it. And also, at the front of the camera, I had a Spectra exposure meter. So I'd look at the exposure meter, get the reading, and transfer it right away to the f-stop - all of which without disturbing the camera or the subject.

FV: How do you imbed yourself in a situation that's unfolding so you can impart to the viewer that experience of being there, while also limiting the effect that you're having on that situation?

AM: I'm not afraid to get very close. Sometimes it's better, for whatever reason, to keep some distance, and I also have the opportunity to get very close with the zoom lens. I find that I'd rather be very close, rather than rely on the zoom. It's one thing for the zoom lens to bring you close, but it's something better for the camera to pick that up, right in the middle of it.

I would also say that being close doesn't necessarily mean being geographically close. If there is something else going on nearby that you could 
include in the shot, which emphasizes even more clearly what's going on, then keep your distance and get that - include that shot.

I find that, in a very important way, many times I would rather see the cinematic work of an amateur than a professional. So many times, professionals rely on fashion, rather than what's actually happening. So, we have such customs as putting the subject over to one side of the screen or the other, but that empty space is a distraction from what's going on. It's not the way you look at people. It puts the subject away, rather than that much closer.

A very big question is one that you put forth: what about the presence of the camera, and how to keep it such that it doesn't interfere with what's going on. Years ago, there was a series of twelve films made by Alan and Susan Raymond, An American Family ${ }^{1}$. And, because I knew him and his wife, I knew that their presumption of how to keep the camera from disturbing what's going on was by having no relationship with the subjects. It's evident in their footage.

What's the expression, about the camera that's not there? If the camera's not there, you say that it's -

FV: A fly on the wall?

AM: Fly on the wall. Direct cinema is anything but a fly on the wall. You have to get in there to get what's really going on. First of all, the cameraperson should have the confidence that their presence is not going to hurt what's going on - that you can maintain the authenticity of the film by being there and recognizing that for yourself and for the subjects. The treatment for it is to have a kindly, trustworthy relationship with the people that you're filming. That can start right from the beginning, so you can film from the very first moment that you meet somebody, because of what's called the gaze. The subjects will pick up something in your eyes that will give you a link with them that allows for full access. And you don't want to lose that. And also - this is important it's the very last moments that you don't want to lose, either, because so much could happen in that moment when you're just about to put down the camera. It's better to hold on to it.

And you maintain that relationship where people are not put off by the camera by not filming when you know that it's going to hurt that person. When they get into a hurtful area, that's when they begin to get conscious of the camera, and you don't want to get that anyway. But, at the same time, you might want to get stuff that's a little borderline, but you have to be very discreet. So

1. An American Family was a controversial twelve episode serialized experimentation in direct cinema created by producer Craig Gilbert for PBS that documented the daily life of the Loud family of southern California. 
if you are discreet, they notice that, and they go on trusting you. It's your discretion and your empathy that keeps it going right. As my mother used to say before I even got into making films, "There's good in everybody". It's particularly important in the case of filming someone that you're disposed to dislike, that you give that person a break, and empathize as much as you can.

FV: I want to return to something you had brought up about the gaze. My favorite scene in any of your films is the "Wild Horses" playback sequence in Gimme Shelter. In fact, I use it when I teach my film theory students narratology, as a way to talk about the subjective camera, and the way it tells a story of a particular moment by both concealing and revealing. I think it perfectly illustrates your painterly technique at work.

AM: Yeah.

FV: But that arresting moment of Charlie Watts returning the gaze is so powerful, when he just turns the gaze back on to the viewer.

AM: Speaking of my work filming them, I always refer to the fact that when I was a child, I think I got a whole course in classical music, just by looking at my father's face as he put on one record after another. And, so... maybe that's got me in that direction of looking at people's faces for expressions. But then, there are all kinds of clues that come from other sources, as well. For example, in Primary, when I filmed Jackie [Kennedy]'s hands, all they wanted was her face - which told something, of course - but not what the hands told. She loved that scene, by the way, and said that she wanted to keep the film. When she saw that, she was like, "I gotta keep this film for my grandchildren".

FV: That's an excellent shot.

AM: And, again, that's an example of exposing somebody's privacy in a very discreet fashion.

FV: Joe McElhaney's recent book [Albert Maysles, 2009] states that you have an interest in filming interior spaces when they're marked by the physical presence of their inhabitants. How do these interactions that subjects have with the spaces they inhabit function as markers of identity? I'm thinking of Grey Gardens, Salesman...

AM: Yeah, there's plenty of examples of that in both of those films. The mess that is Big Edie's bed... the wonderful thing, the radio that they're listening to... the cats that are hanging around, the raccoons... the hole in the wall... Of course, each one of them was providing environment for the both of them. And Salesman, thank God there was a piano in that room, and thank God that 
that girl chose to play the music that she came up with! It was so appropriate to the mental state of the salesmen. So, oftentimes, there's something going on at the same time, and it's appropriate to be in the film - it takes us further inside.

There are two or three words that I find so useful in describing the heart of what I like to do. I like to capture and transmit the experience of whomever it is that I'm filming, and to do it in such a way as to further reveal their humanity. The television commercial is full of no experience, and lack of humanity. In fact, it's the greatest use of the audiovisual medium in dehumanizing us. It could be otherwise; it could serve the purpose of the advertiser better, and serve the needs of us as human beings better.

For example, I want to make a commercial for a certain product that I'll reveal in a moment. I go to a hospital, and wait for a woman to give birth. I start filming when the infant is being handed over to her. I go on filming maybe the husband is there. Sometimes, the eyes of the infant open up. But I get all of what her experience is, including the moment where there's a trickle of tears, and then they reach for a Kleenex - which is the product I'm trying to sell. I mean, think about it - you know what that would put on the screen? It's so, so different to [what currently exists]. And, hopefully, it would start a whole new wave of direct cinema invading commercial-making, because that's a good example of [its use].

FV: What would you say is the ideology behind your filmmaking practice?

AM: I've gotten into it somewhat. A lot of it is what we learn from religion - love thy neighbor.

My philosophy is that audiovisual recordings give us a unique opportunity to capture reality. So many times, something has happened in our lives, and we say to people, "You should have been there". Well, you don't have to say that if a good direct cinema filmmaker was there. And, in fact, because such an effort - with the right tools, and the right frame of mind - such an effort is made to capture what's going on very authentically, you're probably even better off seeing the film than actually being there [chuckles]. Such an effort is made to get it right, and in such a form that it's transmitted so that people pick up on all the subtleties. But, still, I don't know. I think that maybe even people who are practicing direct cinema, but not in its purest form, they're out to prove a point of view, which is not what I do. I think you can understand better what direct cinema is by contrasting it with what, say, Michael Moore does. He has used this term himself, in describing what he does, that he's out to get people. It's quite different. 
FV: I read that you find even Frederick Wiseman's early films problematic for that very reason.

AM: Yeah. It's just one side against the other, and defending one side. As a matter of fact - what was his first film?

FV: Titicut Follies [1967].

AM: Yeah. At some point, I had learned that they were already making the reforms [in Massachusetts mental health institutions] while they were filming, and those reforms weren't depicted in the film.

FV: Really? Was there ever any overlap or dialogue between you and Wiseman? It seems like you, Pennebaker and Leacock were off exploring one end, and Wiseman was doing something else.

AM: Yeah, we never really had much conversation. It was very clear to all of us that we were doing something different. What's interesting is that all four of us - I'm pretty sure - never detoured from our philosophical commitments.

FV: Would you say your philosophical concerns are just as important to your filmmaking practice as your technique?

AM: Yes, it's all connected.

FV: One of the things that I find fascinating about direct cinema is - because it was so very much of its time, and depicted contemporary experiences - the way it provides unique access to a very specific historical moment. What do you think your films reveal about the mid-twentieth century American experience?

AM: Oh. You should really talk to Norman Mailer, if he were alive, because he's quoted as saying that Salesman probably tells more about America than any other film.

FV: That's interesting. As I've been doing academic research on your work and direct cinema, and reading a lot that was written about both, particularly in the ' 70 s and ' 80 s, a lot of academics criticized direct cinema for supposedly naïve assumptions about the nature of reality, truth, and filmmaking. Do you feel like your work and yourself have been misrepresented?

AM: Yeah, in two ways. For one thing, because I'm a psychologist, I'm that much more conscious, I think, about being fair to the people that I'm filming and open-minded, and not working with some preconceived idea.

In the case of Grey Gardens, all too many reviewers thought that this was an abuse of these two women, because they're so crazy. Well, they're not 
crazy [laughs]. In their own way, they can get along with each other, and their openness is not a sign of craziness, but of good health. They took advantage of the biography-making camera to do an autobiography, in effect. And when they saw the film, they adored it. If you were to compare these two women with the wealthy people in their neighborhood - the divorces and all kinds of maladjustments - you might even argue that they were better off. One of the reasons that they're so admired by gay men is that they found a way of opening up, and by maintaining their own beliefs and maintaining their values. They're nonconformist in the healthiest fashion.

One of the reviewers of Grey Gardens ended the review by saying that there are just some people who shouldn't be filmed. I would say just the opposite. When Mrs. Beale was dying, Edie turned to her and said, "Is there anything more you want to say?" and she said, "There's nothing more to say. It's all in the film".

And then I feel - well, in a very broad sense - Salesman connects us with our materialistic world. They have to sell this Bible - with the color photographs and the expensive cover... There's abuse all the way around - abuse of these poor families who really can't afford a 50 dollar Bible.

I discovered later on that they just hated the work they were doing. So the system had both salesman and customer locked into something that neither one of them wanted there. They had to do it. The story that's being told about Paul Brennan, the main character, is particularly captivating that way. He's a guy that obviously has raw sensitivity, above and beyond having to sell something. In fact, his humanistic spirit, I think, probably had more to do with not being able to sell, more than anything else. By the way, they all took to the film.

FV: I'd like to talk a bit about your recent work. When I saw The Love We Make [2011] last year, and it strongly affected me, because it brought back memories of the aftermath of September 11th. ${ }^{2}$ I was a college freshman in Philadelphia at the time, and I remember there being such an eerie atmosphere to those weeks that followed. It was a strange time.

AM: Yeah.

FV: What's the status of In Transit? ${ }^{3}$

2. The Love We Make follows Paul McCartney's experiences in New York in the immediate aftermath of the attacks on the World Trade Center and his organization of the Concert for New York City.

3. In Transit is Maysles' long-gestating documentary about encounters with passengers on trains and destinations known and unknown. It saw completion before his passing and was selected to premiere at the 2015 Tribeca Film Festival. 
AM: Right now, I'm putting together some stuff to send off to this very, very rich guy. There's a strong likelihood that I may get the money for it. I got halfway along by getting a grant from the Ford Foundation worth $\$ 350,000$. He's a multi-, multi-, multi-millionaire - and I know this from Google - and he's very fond of photography [chuckles].

FV: I watched the short nine-minute promo that's online. The train has clearly been a site of fascination for you since your youth.

AM: You mean when I went off to the army?

FV: Yes.

AM: Yeah, yeah. I looked out the window and there was my family, looking at the train, but really at me, but not seeing me.

Of course, I could read exactly what was going on in their mind: "Is he going to come back?" 